\title{
A Family of Bayes Estimators for the Parameters of the Generalized Gamma Distribution
}

\author{
Navid Feroze \\ Department of Statistics, Riphah International University Islamabad, Pakistan \\ navidferoz@gmail.com \\ Muhammad Aslam \\ Department of Statistics, Riphah International University Islamabad, Pakistan \\ aslamsdqu@yahoo.com
}

\begin{abstract}
The paper aims to propose a family of estimators for the Bayesian analysis of three parametric generalized gamma (GG) distribution under different priors and loss functions. We have proposed the Gibbs sampler to obtain the numerical solutions for the point and interval estimators of the parameters using WinBugs. The comparison among the different estimators has been made in terms of posterior risks and the widths of the corresponding credible intervals. A simulation study has been conducted to investigate the performance of the estimators under different combinations of the parametric values and using various sample sizes. A real life data set has been analyzed to illustrate the practical applicability of the results.
\end{abstract}

Keywords: Loss functions; MCMC; Bayesian analysis; Credible intervals

\section{Introduction}

The generalized gamma (GG) distribution introduced by Stacy (1962) offers a flexible family and many of the important lifetime models (such as Weibull, gamma and exponential models) can be obtained as special cases, although the model has applications in several other fields too. The flexibility of the generalized gamma model, however, occurs at the cost of its increased complexity. Gomes et al. (2008) proposed a new estimation method for parameters of the GG distribution. The algorithm has been implemented in Splus and the results have been validated on the particular cases of the generalized gamma distribution. Chen and Lio (2009) obtained the maximum likelihood estimates for the parameters of the GG distribution based on the progressively type-II censored sample. Xie and Liu (2009) analytically derived a three-moment theoretical expression for the auto-conversion rates of the number concentration, mass content, and radar reflectivity based on the generalized gamma distribution function for cloud droplet size distributions. Khodabin and Ahmadabadi (2010) considered the GG distribution and presented a new moment estimation method of parameters using its characterization, MLE for gamma subfamily, entropy representation, Kullback-Leibler discrimination, Akaike and Bayesian information criterion. Mukherjee et al. (2010) used the simulation study to carry out a thorough comparison of the generalized gamma distribution with its components under a Bayesian framework. A real data set has been considered for the purpose of illustration. The paper proceeds by checking compatibility of the various component models with the given data set and finally compares the models to select the one that is most pertinent with the data. But detailed simulation study is not provided in the paper. Badi et al. (2012) used the GG distribution to model the breast cancer survival data under different conditions of the proportional hazards and accelerated failure time assumptions. Ali et al. (2012) considered the problem of estimating $\mathrm{R}=\mathrm{P}(\mathrm{Y}<\mathrm{X})$, where 
$\mathrm{X}$ and $\mathrm{Y}$ are distributed independently as generalized gamma distributions. They also considered the Bayesian analysis under exponential prior using importance sampling. Saha and Shimamura (2012) proposed a family of Bayesian estimators for single channel speech enhancement. The Bayesian estimators, which utilize the cost function of the logspectral amplitude (LSA) estimator, are based on generalized Gamma distribution under speech presence probability. Noufaily and Jones (2013) explored the computational aspects of likelihood maximization for the generalized gamma (GG) distribution. They formulated a version of the score equations such that the equations involved are individually uniquely solvable. Zaks and Korolev (2013) proved a general theorem establishing necessary and sufficient conditions for the convergence of the distributions of sums of a random number of independent identically distributed random variables to variance-generalized-gamma-distributions. The classical and Bayesian analysis of other types of the gamma distribution can be seen from the works of Balakrishnan and Chand (1994), Chung and Kang (1998), Gupta et al. (1998), Shawkyand and Bakoban (2008), Ergashev (2009), Shawky and Bakoban (2009a), Shawky and Bakoban (2009b), Kumar and Shukla (2010), Persson and Ryden (2010), Ghanizadeh et al. (2011), Khan and Kumar (2011) and Singh et al. (2011).

The probability density function (pdf) of the generalized gamma model in its standard form can be written as

$$
f(x, \alpha, \beta, \mu)=\frac{\mu}{\Gamma(\alpha)} \beta^{\mu \alpha} x^{\mu \alpha-1} e^{-(\beta x)^{\mu}} \quad, x, \alpha, \mu, \beta>0
$$

where the parameter $\beta$ is the scale parameter and both $\alpha$ and $\mu$ determine the shape of the distribution. The distribution reduces to the two-parameter Weibull for $\alpha=1$, the twoparameter gamma for $\mu=1$, and the one-parameter exponential for both $\mu=\alpha=1$. Thus, the generalized gamma family incorporates all the important life-testing distributions and this is perhaps the reason that the model has enough scope in lifetime data analyses. Inferential procedures for the generalized gamma distribution are, however, difficult perhaps because of an additional shape parameter.

The likelihood function for the GG distribution using a sample of size ' $n$ ' can be derived as:

$$
L(\alpha, \beta, \mu \mid \mathrm{x})=\left\{\frac{\mu}{\Gamma(\alpha)}\right\}^{n} \beta^{n \mu \alpha}\left\{\prod_{i=1}^{n} x_{i}^{\mu \alpha-1}\right\} e^{-\sum_{i=1}^{n}\left(\beta x_{i}\right)^{\mu}}
$$

\section{Prior and Posterior Distributions}

Bayesian methods can provide more precision of estimate than the classical methods of inference. This happens due to additional information that is present in terms of prior information and the estimates are obtained from the combined sources of information. Thus Bayesian inference is one that modifies one's initial probability statements about the parameters before observing the data to updated or posterior knowledge that combines both prior information and the data at hand. Therefore, prior subject-matter knowledge about a parameter is a vital aspect of the inference process. The prior distributions can be categorized into informative and non-informative priors. As their names suggest, the informative priors are used when the prior information regarding the 
current experiment is available (may be in form of prior beliefs), while when such prior information is not available the use of non-informative priors become inevitable. In order to make our analysis versatile, we have assumed both informative and non-formative priors for the for Bayesian analysis of the parameters of the GG model.

The Jeffreys, gamma and inverse levy priors have been assumed for the estimation of the parameters $\Phi=(\alpha, \beta, \mu)$. These are defined as under:

$$
\begin{aligned}
& p(\Phi) \propto \frac{1}{\Phi} \\
& p(\Phi)=\frac{b^{a}}{\Gamma(a)} \Phi^{a-1} e^{-b \Phi}
\end{aligned}
$$

where $a, b>0$ are the hyper-parameters.

$$
p(\Phi)=\sqrt{\frac{c}{2 \pi}} \Phi^{-\frac{1}{2}} e^{-\left(\frac{c \Phi}{2}\right)}
$$

where $c>0$ is the hyper-parameter.

Now the posterior distribution under each prior can be obtained as:

$$
g(\alpha, \beta, \mu \mid \mathrm{x})=\frac{p(\Phi)\left\{\frac{\mu}{\Gamma(\alpha)}\right\}^{n} \beta^{n \mu \alpha}\left\{\prod_{i=1}^{n} x_{i}^{\mu \alpha-1}\right\} e^{-\sum_{i=1}^{n}\left(\beta x_{i}\right)^{\mu}}}{\int_{0}^{\infty} p(\Phi)\left\{\frac{\mu}{\Gamma(\alpha)}\right\}^{n} \beta^{n \mu \alpha}\left\{\prod_{i=1}^{n} x_{i}^{\mu \alpha-1}\right\} e^{-\sum_{i=1}^{n}\left(\beta x_{i}\right)^{\mu}} d \Phi}
$$

The posterior distribution under Jeffreys prior is:

$$
g(\alpha, \beta, \mu \mid \mathrm{x})=\frac{\frac{1}{\alpha \mu \beta}\left\{\frac{\mu}{\Gamma(\alpha)}\right\}^{n} \beta^{n \mu \alpha}\left\{\prod_{i=1}^{n} x_{i}^{\mu \alpha-1}\right\} e^{-\sum_{i=1}^{n}\left(\beta x_{i}\right)^{\mu}}}{\int_{0}^{\infty} \int_{0}^{\infty} \int_{0}^{\infty} \frac{1}{\alpha \mu \beta}\left\{\frac{\mu}{\Gamma(\alpha)}\right\}^{n} \beta^{n \mu \alpha}\left\{\prod_{i=1}^{n} x_{i}^{\mu \alpha-1}\right\} e^{-\sum_{i=1}^{n}\left(\beta x_{i}\right)^{\mu}} d \alpha d \mu d \beta}
$$

The posterior distribution under gamma prior $\mathrm{i}$

$$
g(\alpha, \beta, \mu \mid \mathrm{x})=\frac{(\alpha \mu \beta)^{a-1} e^{-b(\alpha+\mu+\beta)}\left\{\frac{\mu}{\Gamma(\alpha)}\right\}^{n} \beta^{n \mu \alpha}\left\{\prod_{i=1}^{n} x_{i}^{\mu \alpha-1}\right\} e^{-\sum_{i=1}^{n}\left(\beta x_{i}\right)^{\mu}}}{\int_{0}^{\infty} \int_{0}^{\infty} \int_{0}^{\infty}(\alpha \mu \beta)^{a-1} e^{-b(\alpha+\mu+\beta)}\left\{\frac{\mu}{\Gamma(\alpha)}\right\}^{n} \beta^{n \mu \alpha}\left\{\prod_{i=1}^{n} x_{i}^{\mu \alpha-1}\right\} e^{-\sum_{i=1}^{n}\left(\beta x_{i}\right)^{\mu}} d \alpha d \mu d \beta}
$$

The posterior distribution under inverse levy prior is:

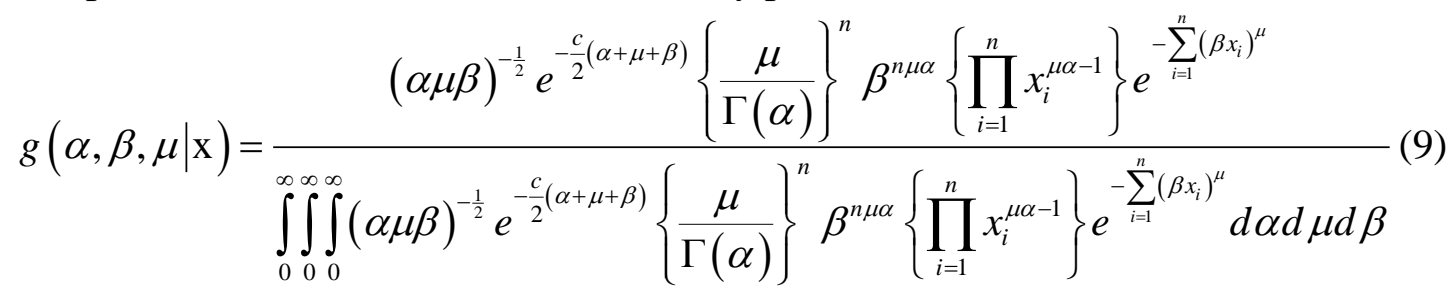




\section{Bayes Estimators and Posterior Risks}

This section discusses the derivation of the Bayes estimator (BE) and corresponding posterior risks (PR) under different loss functions. The Bayes estimators are evaluated under squared error loss function (SELF) and precautionary loss function (PLF). The Bayes estimator (BE) and corresponding posterior risks (PR) under different loss functions are given in the following Table.

Table 1: Bayes estimator and posterior risks under different loss functions

\begin{tabular}{|l|l|l|}
\hline Loss Function $=L(\Phi, \hat{\Phi})$ & Bayes Estimator & Posterior Risk \\
\hline SELF: $\quad(\Phi-\hat{\Phi})^{2}$ & $\mathrm{E}(\Phi \mid \mathrm{x})$ & $\mathrm{E}\left(\Phi^{2} \mid \mathrm{x}\right)-\{\mathrm{E}(\Phi \mid \mathrm{x})\}^{2}$ \\
\hline PLF: $\quad \frac{(\Phi-\hat{\Phi})^{2}}{\hat{\Phi}}$ & $\sqrt{\mathrm{E}\left(\Phi^{2} \mid \mathrm{x}\right)}$ & $2\left\{\sqrt{\mathrm{E}\left(\Phi^{2} \mid \mathrm{x}\right)}-\mathrm{E}(\Phi \mid \mathrm{x})\right\}$ \\
\hline
\end{tabular}

The expressions for the Bayes estimator and posterior risk for $\alpha$ under SELF using Jeffreys prior are:

$$
\begin{aligned}
& \mathrm{E}(\alpha \mid \mathrm{x})=\frac{\int_{0}^{\infty} \int_{0}^{\infty} \int_{0}^{\infty} \frac{1}{\mu \beta}\left\{\frac{\mu}{\Gamma(\alpha)}\right\}^{n} \beta^{n \mu \alpha}\left\{\prod_{i=1}^{n} x_{i}^{\mu \alpha-1}\right\} e^{-\sum_{i=1}^{n}\left(\beta x_{i}\right)^{\mu}} d \alpha d \mu d \beta}{\int_{0}^{\infty} \int_{0}^{\infty} \int_{0}^{\infty} \frac{1}{\alpha \mu \beta}\left\{\frac{\mu}{\Gamma(\alpha)}\right\}^{n} \beta^{n \mu \alpha}\left\{\prod_{i=1}^{n} x_{i}^{\mu \alpha-1}\right\} e^{-\sum_{i=1}^{n}\left(\beta x_{i}\right)^{\mu}} d \alpha d \mu d \beta}
\end{aligned}
$$

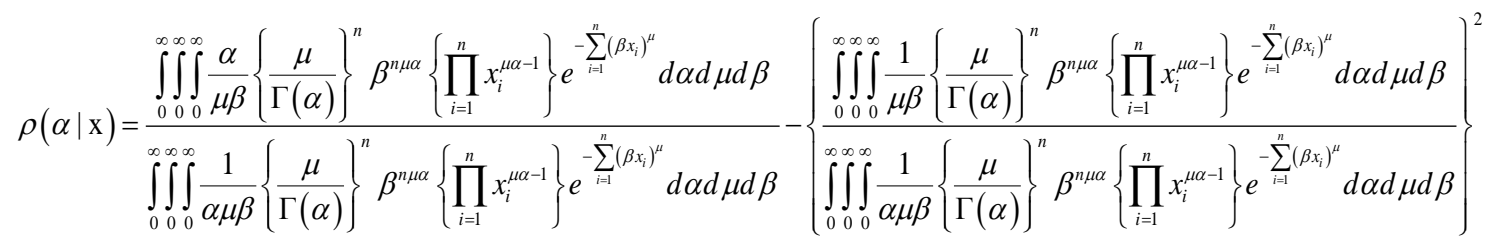

The expressions for the Bayes estimator and posterior risk for $\mu$ under SELF using Jeffreys prior are:

$$
\begin{aligned}
& \mathrm{E}(\mu \mid \mathrm{x})=\frac{\int_{0}^{\infty} \int_{0}^{\infty} \int_{0}^{\infty} \frac{1}{\alpha \beta}\left\{\frac{\mu}{\Gamma(\alpha)}\right\}^{n} \beta^{n \mu \alpha}\left\{\prod_{i=1}^{n} x_{i}^{\mu \alpha-1}\right\} e^{-\sum_{i=1}^{n}\left(\beta x_{i}\right)^{\mu}} d \alpha d \mu d \beta}{\int_{0}^{\infty} \int_{0}^{\infty} \int_{0}^{\infty} \frac{1}{\alpha \mu \beta}\left\{\frac{\mu}{\Gamma(\alpha)}\right\}^{n} \beta^{n \mu \alpha}\left\{\prod_{i=1}^{n} x_{i}^{\mu \alpha-1}\right\} e^{-\sum_{i=1}^{n}\left(\beta x_{i}\right)^{\mu}} d \alpha d \mu d \beta} \\
& \left.\rho(\mu \mid \mathrm{x})=\frac{\iint_{0}^{\infty} \int_{0}^{\infty} \frac{\mu}{\alpha \beta}\left\{\frac{\mu}{\Gamma(\alpha)}\right\}^{n} \beta^{n \mu \alpha}\left\{\prod_{i=1}^{n} x_{i}^{\mu \alpha-1}\right\} e^{-\sum_{i=1}^{n}\left(\beta x_{i}\right)^{\mu}} d \alpha d \mu d \beta}{\iint_{0}^{\infty} \int_{0}^{\infty} \frac{1}{\alpha \mu \beta}\left\{\frac{\mu}{\Gamma(\alpha)}\right\}^{n} \beta^{n \mu \alpha}\left\{\prod_{i=1}^{n} x_{i}^{\mu \alpha-1}\right\} e^{-\sum_{i=1}^{n}\left(\beta x_{i}\right)^{\mu}} d \alpha d \mu d \beta}-\left\{\frac{\int_{0}^{\infty} \frac{1}{\alpha} \frac{1}{\alpha \beta}\left\{\frac{\mu}{\Gamma(\alpha)}\right\}^{n} \beta^{n} \int_{0}^{n \mu \alpha} \frac{1}{\alpha \mu \beta}\left\{\prod_{i=1}^{n} x_{i}^{\mu \alpha-1}\right\} e^{-\sum_{i=1}^{n}\left(\beta x_{i}\right)^{\mu}} d \alpha d \mu d \beta}{\Gamma(\alpha)}\right\}^{n} \beta^{n \mu \alpha}\left\{\prod_{i=1}^{n} x_{i}^{\mu \alpha-1}\right\} e^{-\sum_{i=1}^{n}\left(\beta x_{i}\right)^{\mu}} d \alpha d \mu d \beta\right\}
\end{aligned}
$$

The expressions for the Bayes estimator and posterior risk for $\beta$ under SELF using Jeffreys prior are: 


$$
\begin{aligned}
& \mathrm{E}(\beta \mid \mathrm{x})=\frac{\int_{0}^{\infty} \int_{0}^{\infty} \int_{0}^{\infty} \frac{1}{\alpha \mu}\left\{\frac{\mu}{\Gamma(\alpha)}\right\}^{n} \beta^{n \mu \alpha}\left\{\prod_{i=1}^{n} x_{i}^{\mu \alpha-1}\right\} e^{-\sum_{i=1}^{n}\left(\beta x_{i}\right)^{\mu}} d \alpha d \mu d \beta}{\int_{0}^{\infty} \int_{0}^{\infty} \int_{0}^{\infty} \frac{1}{\alpha \mu \beta}\left\{\frac{\mu}{\Gamma(\alpha)}\right\}^{n} \beta^{n \mu \alpha}\left\{\prod_{i=1}^{n} x_{i}^{\mu \alpha-1}\right\} e^{-\sum_{i=1}^{n}\left(\beta x_{i}\right)^{\mu}} d \alpha d \mu d \beta} \\
& \rho(\beta \mid \mathrm{x})=\frac{\iint_{0}^{\infty} \int_{0}^{\infty} \frac{\beta}{\alpha \mu}\left\{\frac{\mu}{\Gamma(\alpha)}\right\}^{n} \beta^{n \mu \alpha}\left\{\prod_{i=1}^{n} x_{i}^{\mu \alpha-1}\right\} e^{-\sum_{i=1}^{n}\left(\beta_{i}\right)^{\mu}} d \alpha d \mu d \beta}{\iint_{0}^{\infty} \int_{0}^{\infty} \frac{1}{\alpha \mu \beta}\left\{\frac{\mu}{\Gamma(\alpha)}\right\}^{n} \beta^{n \mu \alpha}\left\{\prod_{i=1}^{n} x_{i}^{\mu \alpha-1}\right\} e^{-\sum_{i=1}^{n}\left(\beta_{i}\right)^{\mu}} d \alpha d \mu d \beta}-\left\{\frac{\int_{0}^{\infty} \int_{0}^{\infty} \frac{1}{\alpha \mu}\left\{\frac{\mu}{\Gamma(\alpha)}\right\}^{n} \beta^{n \mu \alpha}\left\{\int_{0}^{\infty} \int_{0}^{\infty} \int_{0}^{\infty} \frac{1}{\alpha \mu \beta} x_{i}^{\mu \alpha-1}\right\} e^{-\sum_{i=1}^{n}\left(\beta x_{i}\right)^{\mu}} d \alpha d \mu d \beta}{\Gamma(\alpha)\}^{n} \beta^{n \mu \alpha}\left\{\prod_{i=1}^{n} x_{i}^{\mu \alpha-1}\right\} e^{-\sum_{i=1}^{n}\left(\beta_{i}\right)^{\mu}} d \alpha d \mu d \beta}\right\}
\end{aligned}
$$

The expressions under SELF using gamma and inverse levy priors can be obtained in the similar manner.

The expressions for the Bayes estimator and posterior risk for $\alpha$ under PLF using Jeffreys prior are:

$$
\begin{aligned}
& \sqrt{\mathrm{E}\left(\alpha^{2} \mid \mathrm{x}\right)}=\left\{\frac{\int_{0}^{\infty} \int_{0}^{\infty} \int_{0}^{\infty} \frac{\alpha}{\mu \beta}\left\{\frac{\mu}{\Gamma(\alpha)}\right\}^{n} \beta^{n \mu \alpha}\left\{\prod_{i=1}^{n} x_{i}^{\mu \alpha-1}\right\} e^{-\sum_{i=1}^{n}\left(\beta x_{i}\right)^{\mu}} d \alpha d \mu d \beta}{\int_{0}^{\infty} \int_{0}^{\infty} \int_{0}^{\infty} \frac{1}{\alpha \mu \beta}\left\{\frac{\mu}{\Gamma(\alpha)}\right\}^{n} \beta^{n \mu \alpha}\left\{\prod_{i=1}^{n} x_{i}^{\mu \alpha-1}\right\} e^{-\sum_{i=1}^{n}\left(\beta x_{i}\right)^{\mu}} d \alpha d \mu d \beta}\right\} \\
& \rho(\alpha \mid \mathrm{x})=2\left[\left\{\frac{\iint_{0}^{\infty} \int_{0}^{\infty} \frac{\alpha}{\mu \beta}\left\{\frac{\mu}{\Gamma(\alpha)}\right\}^{n} \beta^{n \mu \alpha}\left\{\prod_{i=1}^{n} x_{i}^{\mu \alpha-1}\right\} e^{-\sum_{i=1}^{n}\left(\beta_{i}\right)^{\mu}} d \alpha d \mu d \beta}{\left[\iint_{0}^{\infty} \int_{0}^{\infty} \frac{1}{\alpha \mu \beta}\left\{\frac{\mu}{\Gamma(\alpha)}\right\}^{n} \beta^{n \mu \alpha}\left\{\prod_{i=1}^{n} x_{i}^{\mu \alpha-1}\right\} e^{-\sum_{i=1}^{n}\left(\beta_{i}\right)^{\mu}} d \alpha d \mu d \beta\right.}\right\}-\frac{\int_{0}^{\infty} \int_{0}^{\infty} \int_{0}^{\infty} \frac{1}{\mu \beta}\left\{\frac{\mu}{\Gamma(\alpha)}\right\}^{n} \beta^{n \mu \alpha}\left\{\prod _ { i = 1 } ^ { n } \int _ { i } ^ { \infty } \int _ { 0 } ^ { \mu \alpha - 1 } \frac { 1 } { \alpha \mu \beta } \left\{\frac{\mu}{\Gamma(\alpha)} e^{-\sum_{i=1}^{n}\left(\beta_{i}\right)^{\mu}} d \alpha d \mu d \beta\right.\right.}{\left.\beta^{n \mu \alpha}\left\{\prod_{i=1}^{n} x_{i}^{\mu \alpha-1}\right\} e^{-\sum_{i=1}^{n}\left(\beta_{i}\right)^{\mu}} d \alpha d \mu d \beta\right]}\right]
\end{aligned}
$$

The expressions for the Bayes estimator and posterior risk for $\mu$ under PLF using Jeffreys prior are:

$$
\begin{aligned}
& \sqrt{\mathrm{E}\left(\mu^{2} \mid \mathrm{x}\right)}=\left\{\frac{\int_{0}^{\infty} \int_{0}^{\infty} \int_{0}^{\infty} \frac{\mu}{\alpha \beta}\left\{\frac{\mu}{\Gamma(\alpha)}\right\}^{n} \beta^{n \mu \alpha}\left\{\prod_{i=1}^{n} x_{i}^{\mu \alpha-1}\right\} e^{-\sum_{i=1}^{n}\left(\beta x_{i}\right)^{\mu}} d \alpha d \mu d \beta}{\iint_{0}^{\infty} \int_{0}^{\infty} \frac{1}{\alpha \mu \beta}\left\{\frac{\mu}{\Gamma(\alpha)}\right\}^{n} \beta^{n \mu \alpha}\left\{\prod_{i=1}^{n} x_{i}^{\mu \alpha-1}\right\} e^{-\sum_{i=1}^{n}\left(\beta x_{i}\right)^{\mu}} d \alpha d \mu d \beta}\right\}
\end{aligned}
$$

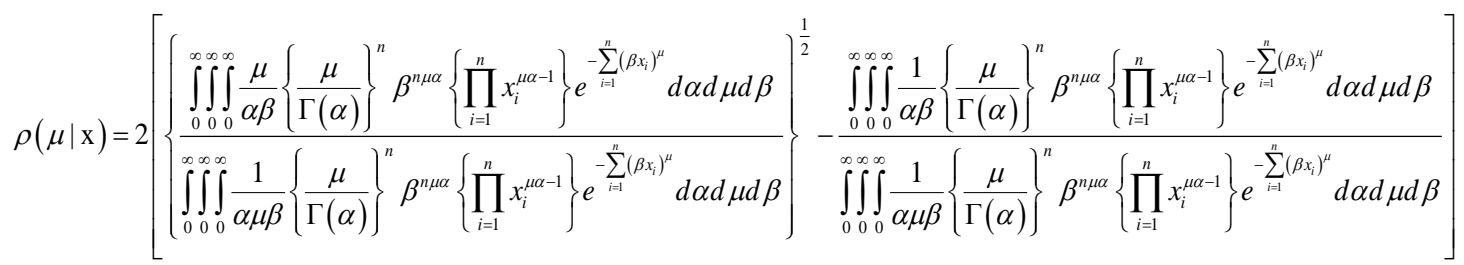


The expressions for the Bayes estimator and posterior risk for $\beta$ under PLF using Jeffreys prior are:

$$
\begin{aligned}
& \sqrt{\mathrm{E}\left(\beta^{2} \mid \mathrm{x}\right)}=\left\{\frac{\int_{0}^{\infty} \int_{0}^{\infty} \int_{0}^{\infty} \frac{\beta}{\alpha \mu}\left\{\frac{\mu}{\Gamma(\alpha)}\right\}^{n} \beta^{n \mu \alpha}\left\{\prod_{i=1}^{n} x_{i}^{\mu \alpha-1}\right\} e^{-\sum_{i=1}^{n}\left(\beta x_{i}\right)^{\mu}} d \alpha d \mu d \beta}{\int_{0}^{\infty} \int_{0}^{\infty} \int_{0}^{\infty} \frac{1}{\alpha \mu \beta}\left\{\frac{\mu}{\Gamma(\alpha)}\right\}^{n} \beta^{n \mu \alpha}\left\{\prod_{i=1}^{n} x_{i}^{\mu \alpha-1}\right\} e^{-\sum_{i=1}^{n}\left(\beta x_{i}\right)^{\mu}} d \alpha d \mu d \beta}\right\} \\
& \rho(\beta \mid \mathrm{x})=2\left[\left\{\left[\frac{\iint_{0}^{\infty} \int_{0}^{\infty} \frac{\beta}{\alpha \mu}\left\{\frac{\mu}{\Gamma(\alpha)}\right\}^{n} \beta^{n \mu \alpha}\left\{\prod_{i=1}^{n} x_{i}^{\mu \alpha-1}\right\} e^{-\sum_{i=1}^{n}\left(\beta x_{i}\right)^{\mu}} d \alpha d \mu d \beta}{\iiint_{0}^{\infty} \frac{1}{\alpha \mu \beta}\left\{\frac{\mu}{\Gamma(\alpha)}\right\}^{n} \beta^{n \mu \alpha}\left\{\prod_{i=1}^{n} x_{i}^{\mu \alpha-1}\right\} e^{-\sum_{i=1}^{n}\left(\beta_{i}\right)^{\mu}} d \alpha d \mu d \beta}\right\}-\frac{\int_{0}^{\infty} \int_{0}^{\infty} \int_{0}^{\infty} \frac{1}{\alpha \mu}\left\{\frac{\mu}{\Gamma(\alpha)}\right\}^{n} \beta^{n \mu \alpha}\left\{\int_{0}^{\infty} \int_{0}^{\infty} \frac{1}{\alpha \mu \beta}\left\{\frac{\mu}{\alpha \mu \alpha-1}\right\}_{i}^{n} e^{-\sum_{i=1}^{n}\left(\beta x_{i}\right)^{\mu}} d \alpha d \mu d \beta\right.}{\Gamma(\alpha)} \beta^{n \mu \alpha}\left\{\prod_{i=1}^{n} x_{i}^{\mu \alpha-1}\right\} e^{-\sum_{i=1}^{n}\left(\beta_{i}\right)^{\mu}} d \alpha d \mu d \beta\right]\right.
\end{aligned}
$$

The expressions under PLF using gamma and inverse levy priors can be obtained in the similar manner.

As the expressions for the Bayes estimators and posterior risks under these loss functions cannot be obtained in a closed form. We have proposed MCMC via Gibbs sampling using WinBugs to obtain the numerical solutions of the estimators.

\subsection{Gibbs Sampler}

The Gibbs sampler is a simulation tool or an algorithm to generate a sequence of samples from a normalized joint density function of two or more random variables. Such samples may be "marginalized" providing samples from the marginal distributions associated with the joint density. Gibbs sampling is applicable when the joint distribution is not known explicitly while the full conditional distribution of each random variable is known and tractable. The sampler requires an initial starting point for the random variables and the data which remains constant throughout (Rouchka (1997)), then one at a time a value for each parameter, or random variable of interest is sampled given values of all the other variables and data, the order in which the parameters are sampled is arbitrary (Marris and Bechger (2005)). Once all the parameters have been sampled, then the process is started over. After a sufficient "burn-in" to remove the effect of initial sampled values, the rest is considered to be dependent and identically distributed sample from the joint distribution.

Consider a problem with three random variables or three parameters $\alpha, \beta$ and $\mu$ in Bayesian analysis context, and let $\mathrm{x}$ denote the data. Suppose further that the full conditional distributions $g(\alpha \mid \beta, \mu, \mathrm{x}), g(\beta \mid \alpha, \mu, \mathrm{x})$ and $g(\mu \mid \alpha, \beta, \mathrm{x})$ are tractable, and we need to find $g(\alpha \mid \mathrm{x}), g(\beta \mid \mathrm{x})$ and $g(\mu \mid \mathrm{x})$. The Gibbs sampler proceeds by choosing some initial values which we will denote by $\alpha_{0}, \beta_{0}, \mu_{0}$ from the parameter space. These can be any reasonable values of $\alpha, \beta, \mu$, and then we take draws from the three conditional distributions in the following sequence: 


$$
\begin{aligned}
& \alpha_{1} \sim g\left(\alpha \mid \beta_{0}, \mu_{0}, \mathrm{x}\right) \quad \alpha_{2} \sim g\left(\alpha \mid \beta_{1}, \mu_{1}, \mathrm{x}\right) \quad \alpha_{m} \sim g\left(\alpha \mid \beta_{m-1}, \mu_{m-1}, \mathrm{x}\right) \\
& \beta_{1} \sim g\left(\beta \mid \alpha_{1}, \mu_{0}, \mathrm{x}\right) \quad, \quad \beta_{2} \sim g\left(\beta \mid \alpha_{2}, \mu_{1}, \mathrm{x}\right), \ldots, \quad \beta_{m} \sim g\left(\beta \mid \alpha_{m}, \mu_{m-1}, \mathrm{x}\right) \\
& \mu_{1} \sim g\left(\mu \mid \alpha_{1}, \beta_{1}, \mathrm{x}\right) \quad \mu_{2} \sim g\left(\mu \mid \alpha_{2}, \beta_{2}, \mathrm{x}\right) \quad \mu_{m} \sim g\left(\mu \mid \alpha_{m}, \beta_{m}, \mathrm{x}\right)
\end{aligned}
$$

This sequence of draws constitutes a Markov chain because the values at step (m) depend on the values at step (m-1). In order to implement the Gibbs sampler for the model (2), we need to extract the conditional distributions from the posterior in (2) for each unknown parameter.

The conditional distribution of the parameter $\alpha, \beta$ and $\mu$ are:

$g(\alpha \mid \beta, \mu, \mathrm{x}) \propto \frac{1}{\alpha}\left\{\frac{1}{\Gamma(\alpha)}\right\}^{n} e^{-\mu \alpha\left(\sum_{i=1}^{n} x_{i}^{-1}-\ln \beta^{n}\right)}$

The density becomes $\alpha \sim \operatorname{Gamma}\left(0, \mu\left(\sum_{i=1}^{n} x_{i}^{-1}-\ln \beta^{n}\right)\right)$

$g(\beta \mid \alpha, \mu, \mathrm{x}) \propto \beta^{n \mu \alpha-1} e^{-\sum_{i=1}^{n}\left(\beta x_{i}\right)^{\mu}}$

putting $\alpha=\mu=1$, then the density becomes $g(\beta \mid \alpha, \mu, \mathrm{x}) \propto \beta^{n-1} e^{-\beta \sum_{i=1}^{n} x_{i}}$

which is a gamma distribution $\beta \sim \operatorname{Gamma}\left(n, \sum_{i=1}^{n} x_{i}\right)$

$g(\mu \mid \alpha, \beta, \mathrm{x}) \propto \mu^{n-1} \beta^{n \mu \alpha}\left\{\prod_{i=1}^{n} x_{i}^{\mu \alpha-1}\right\} e^{-\sum_{i=1}^{n}\left(\beta x_{i}\right)^{\mu}}$

which is a log-concave as: $\frac{\partial^{2} \ln g(\mu \mid \alpha, \beta, \mathrm{x})}{\partial \mu^{2}}=-\left\{\frac{n-1}{\mu}+\sum_{i=1}^{n} x_{i}^{\mu}\left(\ln x_{i}\right)^{2}\right\}<0$

\section{Algorithm:}

Step 1: Generate $\mu$ from the log-concave density function (12) using the method proposed by Devroye (1984).

Step 1: Generate $\beta$ from Gamma $\left(n, \sum_{i=1}^{n} x_{i}\right)$

Step 2: Generate $\alpha$ from Gamma $\left(0, \mu_{1}\left(\sum_{i=1}^{n} x_{i}^{-1}-\ln \beta_{1}^{n}\right)\right)$

Step 3: Obtain the posterior samples $\left(\alpha_{1}, \beta_{1}, \mu_{1}\right), \ldots,\left(\alpha_{m}, \beta_{m}, \mu_{m}\right)$ by repeating the Steps 1 and $2, \mathrm{~m}$ times. 
Now, the Bayes estimate and posterior risks under SELF can be obtained by using the formulae $\Phi_{S E L F}=\frac{\sum_{i=1}^{m} \Phi_{i}}{m}$ and $\rho\left(\Phi_{S E L F}\right)=\sum_{i=1}^{m}\left(\Phi_{i}-\Phi_{S E L F}\right)^{2}$. Similarly the Bayes estimate and posterior risk under PLF can be calculated by using the formula $\mathrm{e}_{\Phi_{P L F}}=\sqrt{\frac{\sum_{i=1}^{m} \Phi_{i}^{2}}{m}}$ and $\rho\left(\Phi_{P L F}\right)=2\left\{\sqrt{\frac{\sum_{i=1}^{m} \Phi_{i}^{2}}{m}}-\frac{\sum_{i=1}^{m} \Phi_{i}}{m}\right\}$.

The curves of the posterior densities of the $\Phi$ using a simulated sample of size 50 from model presented in (6).

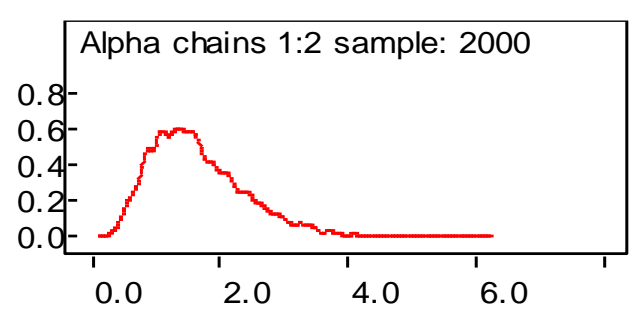

Fig. 1: Marginal posterior distribution of $\alpha$ under Jeffreys prior

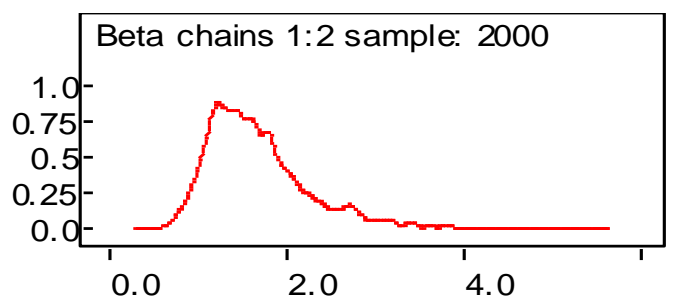

Fig. 2: Marginal posterior distribution of $\beta$ under Jeffreys prior

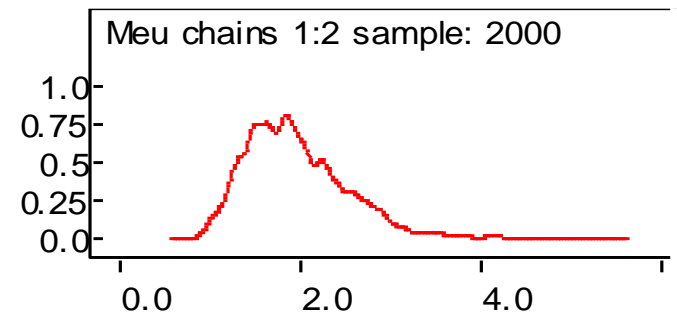

Fig. 3: Marginal posterior distribution of $\mu$ under Jeffreys prior

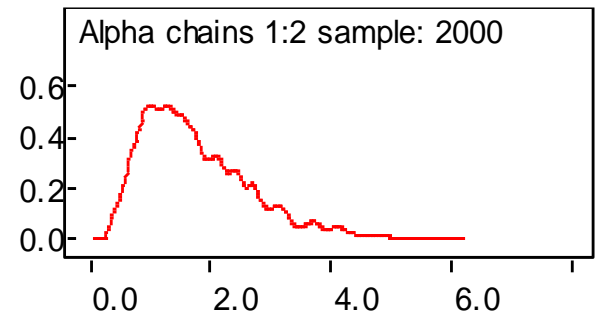

Fig. 4: Marginal posterior distribution of $\alpha$ under inverse levy prior

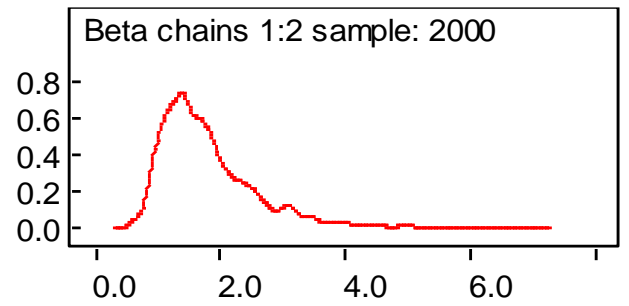

Fig. 5: Marginal posterior distribution of $\beta$ under inverse levy prior

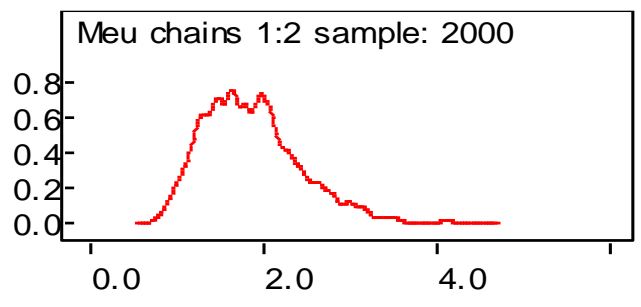

Fig. 6: Marginal posterior distribution of $\mu$ under inverse levy prior 


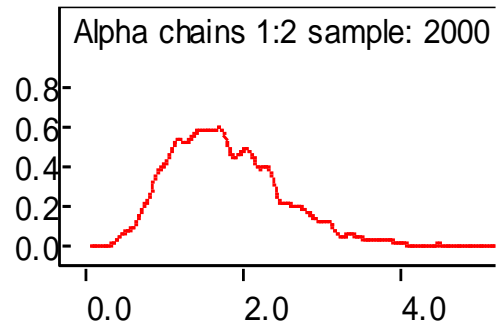

Fig. 7: Marginal posterior distribution of $\alpha$ under gamma prior

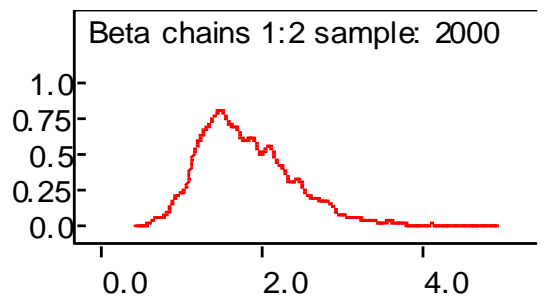

Fig. 8: Marginal posterior distribution of $\beta$ under gamma prior

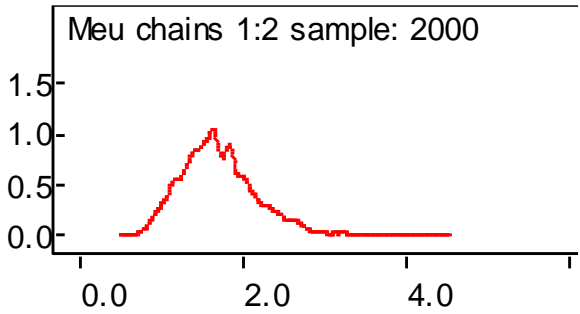

Fig. 9: Marginal posterior distribution of $\mu$ under gamma prior

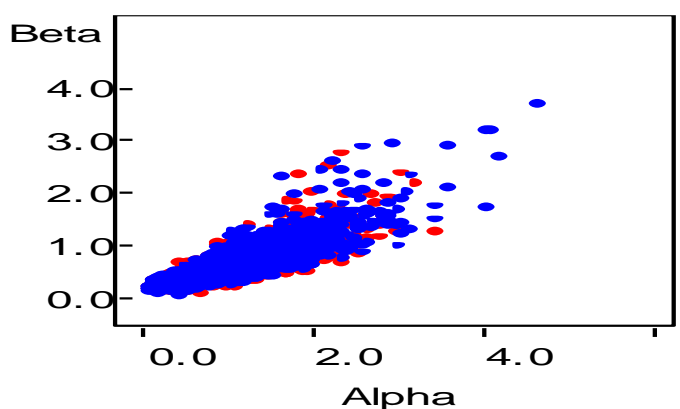

Fig. 10: The Bivariate posterior distribution of $\beta$ and $\alpha$ unc gamma prior

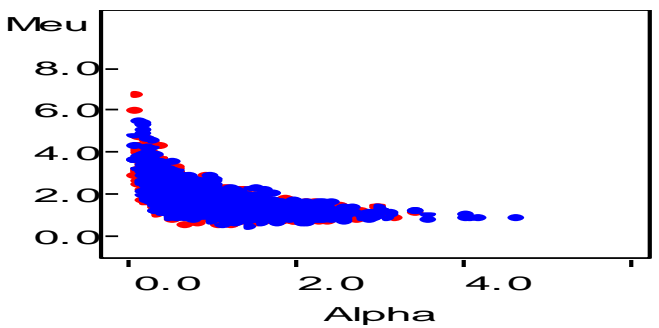

Fig. 11: The Bivariate posterior distribution of $\mu$ and $\alpha$ under gamma prior

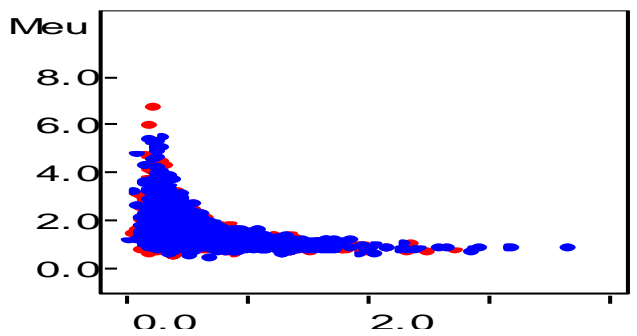

Fig. 12: The Bivariate posterior distribution of $\mu$ and $\beta$ under gamma prior

\subsection{Credible Intervals}

Samaniego (2010) has discussed that unlike the classical inference; the notion of interval estimation under Bayesian inference is simpler and manages to avoid potential conflicts with the observed data. The posterior distribution of the parameter $\Phi$ comprises the basis for all Bayesian inference about $\Phi$. The Bayesian counterpart of a confidence interval for $\Phi$ is called a credible interval for $\Phi$, and is obtained from the posterior distribution by selecting an interval corresponding to the probability level desired. For example, any interval $\left(\Phi_{L}, \Phi_{U}\right)$ for which $\int_{\Phi_{L}}^{\Phi_{U}} g(\Phi \mid \mathrm{x}) d \Phi=1-k$ is the $100(1-k) \%$ credible intervals for $\Phi$, where $g(\Phi \mid \mathrm{x})$ is the posterior density of $\Phi$ and $k$ is level of significance. The credible interval used most often is the central one in which the limits $\left(\Phi_{L}, \Phi_{U}\right)$ are 
chosen to satisfy $\int_{-\infty}^{\Phi_{L}} g(\Phi \mid \mathrm{x}) d \Phi=\frac{k}{2}=\int_{\Phi_{U}}^{\infty} g(\Phi \mid \mathrm{x}) d \Phi$. Credible intervals represent the statistician's posterior judgment about intervals that contain $\Phi$ with a given probability. They are clearly in harmony with the likelihood principle. Now the numerical solutions for the credible intervals for $\Phi$ have been obtained using the Gibbs sampler.

\section{Simulation Study}

In this section a simulation study has been used to investigate the performance of the proposed estimators. The comparisons have been made with respect to different sample sizes, true values of the parameters, different values of the hyper-parameters under a class of priors using a couple of loss functions. We have chosen the values of the hyperparameters so that the prior means are close to the true values of the concerned parameter.

We have generated 2000 MCMC samples from the posterior distributions for the Bayes estimation of the parameters. All these results are based on the average of 1,000 repetitions. The $95 \%$ credible intervals have also been computed using the MCMC samples. The amounts of posterior risks associated with the Bayes estimates have been reported in the parenthesis, while the widths of the $95 \%$ credible intervals have been denoted by ' $\delta$ '. 
Table 2: Bayes estimators and posterior risks under Jeffreys prior using different loss functions

\begin{tabular}{|c|c|c|c|c|c|c|c|}
\hline \multirow{2}{*}{$(\alpha, \beta, \mu)$} & \multirow{2}{*}{$\mathrm{N}$} & \multicolumn{3}{|c|}{ SELF } & \multicolumn{3}{|c|}{ PLF } \\
\hline & & $\hat{\alpha}$ & $\hat{\beta}$ & $\hat{\mu}$ & $\hat{\alpha}$ & $\hat{\beta}$ & $\hat{\mu}$ \\
\hline \multirow{3}{*}{$\begin{array}{c}(1.5,2.0, \\
1.8)\end{array}$} & 50 & $\begin{array}{c}1.729878 \\
(0.795487) \\
\end{array}$ & $\begin{array}{c}1.822336 \\
(0.723012) \\
\end{array}$ & $\begin{array}{c}1.874996 \\
(0.552196) \\
\end{array}$ & $\begin{array}{c}1.781247 \\
(0.102738) \\
\end{array}$ & $\begin{array}{c}1.862379 \\
(0.080087) \\
\end{array}$ & $\begin{array}{c}1.914288 \\
(0.078583) \\
\end{array}$ \\
\hline & 70 & $\begin{array}{c}1.622186 \\
(0.668407)\end{array}$ & $\begin{array}{c}1.880150 \\
(0.595915)\end{array}$ & $\begin{array}{c}1.831409 \\
(0.526210)\end{array}$ & $\begin{array}{c}1.661717 \\
(0.079062)\end{array}$ & $\begin{array}{c}1.911242 \\
(0.062184)\end{array}$ & $\begin{array}{c}1.861072 \\
(0.059326)\end{array}$ \\
\hline & 100 & $\begin{array}{c}1.537639 \\
(0.574916)\end{array}$ & $\begin{array}{c}1.981247 \\
(0.558659)\end{array}$ & $\begin{array}{c}1.816399 \\
(0.483196)\end{array}$ & $\begin{array}{c}1.562754 \\
(0.050230)\end{array}$ & $\begin{array}{c}2.004580 \\
(0.046665) \\
\end{array}$ & $\begin{array}{c}1.838528 \\
(0.044259) \\
\end{array}$ \\
\hline \multirow{3}{*}{$\begin{array}{c}(15.0, \\
2.0,1.8)\end{array}$} & 50 & $\begin{array}{l}14.186341 \\
(3.273655)\end{array}$ & $\begin{array}{c}1.814194 \\
(0.916776)\end{array}$ & $\begin{array}{c}1.852018 \\
(0.612865)\end{array}$ & $\begin{array}{c}14.323880 \\
(0.275078)\end{array}$ & $\begin{array}{c}1.857687 \\
(0.086986)\end{array}$ & $\begin{array}{c}1.892680 \\
(0.081324)\end{array}$ \\
\hline & 70 & $\begin{array}{c}14.766535 \\
(2.750684)\end{array}$ & $\begin{array}{c}1.871750 \\
(0.755617) \\
\end{array}$ & $\begin{array}{c}1.808965 \\
(0.584024) \\
\end{array}$ & $\begin{array}{l}14.831050 \\
(0.129030) \\
\end{array}$ & $\begin{array}{c}1.904575 \\
(0.065650) \\
\end{array}$ & $\begin{array}{c}1.840616 \\
(0.063302) \\
\end{array}$ \\
\hline & 100 & $\begin{array}{r}14.923753 \\
(2.365943) \\
\end{array}$ & $\begin{array}{c}1.972396 \\
(0.708377) \\
\end{array}$ & $\begin{array}{c}1.794138 \\
(0.536284) \\
\end{array}$ & $\begin{array}{l}14.971710 \\
(0.095916) \\
\end{array}$ & $\begin{array}{c}1.997596 \\
(0.050401) \\
\end{array}$ & $\begin{array}{c}1.816715 \\
(0.045152) \\
\end{array}$ \\
\hline \multirow{3}{*}{$\begin{array}{c}(1.5, \\
20.0, \\
1.8)\end{array}$} & 50 & $\begin{array}{c}1.779381 \\
(0.788651) \\
\end{array}$ & $\begin{array}{r}20.736453 \\
(3.065463) \\
\end{array}$ & $\begin{array}{c}1.847081 \\
(0.499018) \\
\end{array}$ & $\begin{array}{c}1.832220 \\
(0.105678)\end{array}$ & $\begin{array}{r}21.192109 \\
(0.911313) \\
\end{array}$ & $\begin{array}{c}1.885788 \\
(0.077413)\end{array}$ \\
\hline & 70 & $\begin{array}{c}1.668607 \\
(0.662663)\end{array}$ & $\begin{array}{l}20.324604 \\
(2.526587)\end{array}$ & $\begin{array}{c}1.804143 \\
(0.475534)\end{array}$ & $\begin{array}{c}1.709270 \\
(0.081325)\end{array}$ & $\begin{array}{l}20.660713 \\
(0.672218) \\
\end{array}$ & $\begin{array}{c}1.833364 \\
(0.058442) \\
\end{array}$ \\
\hline & 100 & $\begin{array}{c}1.483178 \\
(0.478921)\end{array}$ & $\begin{array}{l}20.108229 \\
(1.952250)\end{array}$ & $\begin{array}{c}1.747759 \\
(0.416114)\end{array}$ & $\begin{array}{c}1.507403 \\
(0.048451)\end{array}$ & $\begin{array}{l}20.345036 \\
(0.473616)\end{array}$ & $\begin{array}{c}1.769053 \\
(0.042587) \\
\end{array}$ \\
\hline \multirow{3}{*}{$\begin{array}{c}(1.5,2.0 \\
18.0)\end{array}$} & 50 & $\begin{array}{c}1.787311 \\
(0.970761)\end{array}$ & $\begin{array}{c}1.867463 \\
(0.147192)\end{array}$ & $\begin{array}{l}18.852615 \\
(4.079675)\end{array}$ & $\begin{array}{c}1.840385 \\
(0.106149)\end{array}$ & $\begin{array}{c}1.908498 \\
(0.082070)\end{array}$ & $\begin{array}{l}19.013909 \\
(0.322588)\end{array}$ \\
\hline & 70 & $\begin{array}{c}1.676044 \\
(0.815681)\end{array}$ & $\begin{array}{c}1.926709 \\
(0.121317)\end{array}$ & $\begin{array}{l}18.230212 \\
(3.887685)\end{array}$ & $\begin{array}{c}1.716887 \\
(0.081687)\end{array}$ & $\begin{array}{c}1.958571 \\
(0.063724)\end{array}$ & $\begin{array}{l}18.367950 \\
(0.275478)\end{array}$ \\
\hline & 100 & $\begin{array}{c}1.588690 \\
(0.701590)\end{array}$ & $\begin{array}{c}1.989704 \\
(0.113733)\end{array}$ & $\begin{array}{l}18.135586 \\
(3.569897)\end{array}$ & $\begin{array}{c}1.614639 \\
(0.051898) \\
\end{array}$ & $\begin{array}{c}2.013136 \\
(0.046864) \\
\end{array}$ & $\begin{array}{r}18.236335 \\
(0.201496) \\
\end{array}$ \\
\hline \multirow{3}{*}{$\begin{array}{l}(15.0 \\
20.0 \\
18.0)\end{array}$} & 50 & $\begin{array}{r}15.536825 \\
(6.136756)\end{array}$ & $\begin{array}{l}20.567253 \\
(1.178950)\end{array}$ & $\begin{array}{l}16.954284 \\
(1.894673)\end{array}$ & $\begin{array}{l}15.998194 \\
(0.922737) \\
\end{array}$ & $\begin{array}{c}0.705813 \\
(0.277120) \\
\end{array}$ & $\begin{array}{l}17.208152 \\
(0.507736) \\
\end{array}$ \\
\hline & 70 & $\begin{array}{r}15.298075 \\
(5.156401)\end{array}$ & $\begin{array}{l}20.370962 \\
(0.971703)\end{array}$ & $\begin{array}{c}17.553763 \\
(1.805510) \\
\end{array}$ & $\begin{array}{l}15.670874 \\
(0.745598) \\
\end{array}$ & $\begin{array}{l}20.487829 \\
(0.233733) \\
\end{array}$ & $\begin{array}{r}17.721762 \\
(0.335997) \\
\end{array}$ \\
\hline & 100 & $\begin{array}{l}15.134600 \\
(3.726644)\end{array}$ & $\begin{array}{l}20.154093 \\
(0.750818)\end{array}$ & $\begin{array}{c}17.855429 \\
(1.579901)\end{array}$ & $\begin{array}{l}15.381801 \\
(0.494403)\end{array}$ & $\begin{array}{l}20.249561 \\
(0.190937)\end{array}$ & $\begin{array}{l}17.994106 \\
(0.277354)\end{array}$ \\
\hline
\end{tabular}


Navid Feroze, Muhammad Aslam

Table 3: Bayes estimators and posterior risks under gamma prior using different loss functions

\begin{tabular}{|c|c|c|c|c|c|c|c|}
\hline \multirow{2}{*}{$\begin{array}{c}(\alpha, \beta, \\
\mu)\end{array}$} & \multirow[b]{2}{*}{$\mathrm{n}$} & \multicolumn{3}{|c|}{ SELF } & \multicolumn{3}{|c|}{ PLF } \\
\hline & & $\hat{\alpha}$ & $\hat{\beta}$ & $\hat{\mu}$ & $\hat{\alpha}$ & $\hat{\beta}$ & $\hat{\mu}$ \\
\hline \multirow{3}{*}{$\begin{array}{l}(1.5, \\
2.0, \\
1.8)\end{array}$} & 50 & $\begin{array}{c}1.697525 \\
(0.718647)\end{array}$ & $\begin{array}{c}1.843471 \\
(0.686512) \\
\end{array}$ & $\begin{array}{c}1.868365 \\
(0.547159) \\
\end{array}$ & $\begin{array}{c}1.746185 \\
(0.097321) \\
\end{array}$ & $\begin{array}{c}1.882094 \\
(0.077247) \\
\end{array}$ & $\begin{array}{c}1.905611 \\
(0.074491) \\
\end{array}$ \\
\hline & 70 & $\begin{array}{c}1.591847 \\
(0.603842)\end{array}$ & $\begin{array}{c}1.901956 \\
(0.565831)\end{array}$ & $\begin{array}{c}1.824932 \\
(0.521410)\end{array}$ & $\begin{array}{c}1.629008 \\
(0.074322) \\
\end{array}$ & $\begin{array}{c}1.931475 \\
(0.059038) \\
\end{array}$ & $\begin{array}{c}1.852636 \\
(0.055407) \\
\end{array}$ \\
\hline & 100 & $\begin{array}{c}1.508881 \\
(0.519382)\end{array}$ & $\begin{array}{c}2.004225 \\
(0.530456)\end{array}$ & $\begin{array}{c}1.809975 \\
(0.478788)\end{array}$ & $\begin{array}{c}1.531993 \\
(0.046224)\end{array}$ & $\begin{array}{c}2.025801 \\
(0.043152)\end{array}$ & $\begin{array}{c}1.830194 \\
(0.040437)\end{array}$ \\
\hline \multirow{3}{*}{$\begin{array}{c}(15.0 \\
2.0 \\
1.8)\end{array}$} & 50 & $\begin{array}{l}13.921021 \\
(2.957437)\end{array}$ & $\begin{array}{c}1.835235 \\
(0.870494)\end{array}$ & $\begin{array}{c}1.845468 \\
(0.607275)\end{array}$ & $\begin{array}{l}14.041932 \\
(0.241821)\end{array}$ & $\begin{array}{c}1.877353 \\
(0.084236)\end{array}$ & $\begin{array}{c}1.884100 \\
(0.077264)\end{array}$ \\
\hline & 70 & $\begin{array}{l}14.490364 \\
(2.484982) \\
\end{array}$ & $\begin{array}{c}1.893458 \\
(0.717471) \\
\end{array}$ & $\begin{array}{c}1.802568 \\
(0.578697) \\
\end{array}$ & & $\begin{array}{c}1.924737 \\
(0.062558) \\
\end{array}$ & $\begin{array}{c}1.832272 \\
(0.059410) \\
\end{array}$ \\
\hline & 100 & $\begin{array}{l}14.644642 \\
(2.137405)\end{array}$ & $\begin{array}{c}1.995271 \\
(0.672616)\end{array}$ & $\begin{array}{c}1.787793 \\
(0.531392)\end{array}$ & $\begin{array}{l}14.677010 \\
(0.064737)\end{array}$ & $\begin{array}{c}2.018743 \\
(0.046943)\end{array}$ & $\begin{array}{c}1.808480 \\
(0.041374)\end{array}$ \\
\hline \multirow{3}{*}{$\begin{array}{c}(1.5 \\
20.0 \\
1.8)\end{array}$} & 50 & $\begin{array}{r}1.74 \\
(0.71\end{array}$ & $\begin{array}{l}20.976949 \\
(2.910708)\end{array}$ & $\begin{array}{c}1.840549 \\
(0.494466)\end{array}$ & $\begin{array}{c}1.796155 \\
(0.100106)\end{array}$ & $\begin{array}{l}21.416452 \\
(0.879005)\end{array}$ & $\begin{array}{c}1.877240 \\
(0.073382)\end{array}$ \\
\hline & 70 & $\begin{array}{c}1.637400 \\
(0.598653)\end{array}$ & $\begin{array}{l}20.560324 \\
(2.399037)\end{array}$ & $\begin{array}{c}1.797763 \\
(0.471196)\end{array}$ & $\begin{array}{c}1.675625 \\
(0.076450)\end{array}$ & $\begin{array}{l}20.879430 \\
(0.638214)\end{array}$ & $\begin{array}{c}1.825053 \\
(0.054582)\end{array}$ \\
\hline & 100 & $\begin{array}{r}1.45 \\
(0.43\end{array}$ & $\begin{array}{l}20.341439 \\
(1.853694)\end{array}$ & $\begin{array}{c}1.741578 \\
(0.412318) \\
\end{array}$ & $\begin{array}{c}1.477732 \\
(0.044585) \\
\end{array}$ & $\begin{array}{l}20.560412 \\
(0.437945) \\
\end{array}$ & $\begin{array}{c}1.761034 \\
(0.038912) \\
\end{array}$ \\
\hline \multirow{3}{*}{$\begin{array}{c}(1.5 \\
2.0 \\
18.0)\end{array}$} & 50 & $\begin{array}{c}1.753884 \\
(0.876990) \\
\end{array}$ & $\begin{array}{c}1.889121 \\
(0.139761) \\
\end{array}$ & $\begin{array}{r}18.785942 \\
(4.042461) \\
\end{array}$ & $\begin{array}{c}1.804159 \\
(0.100551) \\
\end{array}$ & $\begin{array}{c}1.928702 \\
(0.079161) \\
\end{array}$ & $\begin{array}{l}18.927719 \\
(0.283554) \\
\end{array}$ \\
\hline & 70 & $\begin{array}{c}1.644698 \\
(0.736890) \\
\end{array}$ & $\begin{array}{c}1.949054 \\
(0.115193) \\
\end{array}$ & $\begin{array}{l}18.165740 \\
(3.852222)\end{array}$ & $\begin{array}{c}1.683092 \\
(0.076789) \\
\end{array}$ & $\begin{array}{c}1.979305 \\
(0.060500) \\
\end{array}$ & $\begin{array}{l}18.284688 \\
(0.237896) \\
\end{array}$ \\
\hline & 10 & $\begin{array}{c}1.558978 \\
(0.633820)\end{array}$ & $\begin{array}{c}2.012780 \\
(0.107991)\end{array}$ & $\begin{array}{c}18.071449 \\
(3.537333)\end{array}$ & $\begin{array}{c}1.582857 \\
(0.047758) \\
\end{array}$ & $\begin{array}{c}2.034447 \\
(0.043335) \\
\end{array}$ & $\begin{array}{l}18.153670 \\
(0.164442) \\
\end{array}$ \\
\hline \multirow{3}{*}{$\begin{array}{l}(15.0, \\
20.0, \\
18.0)\end{array}$} & 50 & $\begin{array}{l}15.246248 \\
(5.543977)\end{array}$ & $\begin{array}{c}20.805787 \\
(1.119433)\end{array}$ & $\begin{array}{r}16.894324 \\
(1.877390)\end{array}$ & $\begin{array}{l}15.683289 \\
(0.874083)\end{array}$ & $\begin{array}{l}20.925008 \\
(0.238442)\end{array}$ & $\begin{array}{l}17.130147 \\
(0.471646)\end{array}$ \\
\hline & 70 & $\begin{array}{l}15.011963 \\
(4.658319)\end{array}$ & $\begin{array}{l}20.607219 \\
(0.922648)\end{array}$ & $\begin{array}{r}17.491683 \\
(1.789041)\end{array}$ & $\begin{array}{l}15.362412 \\
(0.700898)\end{array}$ & $\begin{array}{c}0.704716 \\
(0.194994)\end{array}$ & $\begin{array}{l}17.641429 \\
(0.299492)\end{array}$ \\
\hline & 100 & $\begin{array}{l}14.851546 \\
(3.366669)\end{array}$ & $\begin{array}{l}20.387835 \\
(0.712914)\end{array}$ & $\begin{array}{c}17.792283 \\
(1.565490)\end{array}$ & $\begin{array}{l}15.079029 \\
(0.454967)\end{array}$ & $\begin{array}{l}20.463926 \\
(0.152182)\end{array}$ & $\begin{array}{l}17.912539 \\
(0.240512)\end{array}$ \\
\hline
\end{tabular}


Table 4: Bayes estimators and posterior risks under inverse levy prior using different loss functions

\begin{tabular}{|c|c|c|c|c|c|c|c|}
\hline \multirow{2}{*}{$(\alpha, \beta, \mu)$} & \multirow{2}{*}{$\mathrm{n}$} & \multicolumn{3}{|c|}{ SELF } & \multicolumn{3}{|c|}{ PLF } \\
\hline & & $\hat{\alpha}$ & $\hat{\beta}$ & $\hat{\mu}$ & $\hat{\alpha}$ & $\hat{\beta}$ & $\hat{\mu}$ \\
\hline \multirow{3}{*}{$\begin{array}{c}(1.5,2.0 \\
1.8)\end{array}$} & 50 & $\begin{array}{c}1.715352 \\
(0.684572)\end{array}$ & $\begin{array}{c}1.837564 \\
(0.707653) \\
\end{array}$ & $\begin{array}{c}1.852683 \\
(0.516734) \\
\end{array}$ & $\begin{array}{c}1.762757 \\
(0.094810)\end{array}$ & $\begin{array}{c}1.876815 \\
(0.078502)\end{array}$ & $\begin{array}{c}1.887724 \\
(0.070083)\end{array}$ \\
\hline & 70 & $\begin{array}{c}1.608564 \\
(0.575211) \\
\end{array}$ & $\begin{array}{c}1.895861 \\
(0.583256) \\
\end{array}$ & $\begin{array}{c}1.809615 \\
(0.492417) \\
\end{array}$ & $\begin{array}{c}1.644468 \\
(0.071807) \\
\end{array}$ & $\begin{array}{c}1.926057 \\
(0.060391) \\
\end{array}$ & $\begin{array}{c}1.835247 \\
(0.051264) \\
\end{array}$ \\
\hline & 100 & $\begin{array}{c}1.524727 \\
(0.494755)\end{array}$ & $\begin{array}{c}1.997803 \\
(0.546791)\end{array}$ & $\begin{array}{c}1.794783 \\
(0.452165)\end{array}$ & $\begin{array}{c}1.546532 \\
(0.043610)\end{array}$ & $\begin{array}{c}2.020118 \\
(0.044630)\end{array}$ & $\begin{array}{c}1.813016 \\
(0.036465)\end{array}$ \\
\hline \multirow{3}{*}{$\begin{array}{c}(15.0,2.0 \\
1.8)\end{array}$} & 50 & $\begin{array}{r}14.067217 \\
(2.817208) \\
\end{array}$ & $\begin{array}{c}1.829354 \\
(0.897301) \\
\end{array}$ & $\begin{array}{c}1.829978 \\
(0.573507) \\
\end{array}$ & $\begin{array}{r}14.175193 \\
(0.215954) \\
\end{array}$ & $\begin{array}{c}1.872086 \\
(0.085465) \\
\end{array}$ & $\begin{array}{c}1.866416 \\
(0.072876) \\
\end{array}$ \\
\hline & 70 & $\begin{array}{l}14.642539 \\
(2.367155)\end{array}$ & $\begin{array}{c}1.887391 \\
(0.739565)\end{array}$ & $\begin{array}{c}1.787438 \\
(0.546518)\end{array}$ & $\begin{array}{l}14.677099 \\
(0.069120)\end{array}$ & $\begin{array}{c}1.919338 \\
(0.063894)\end{array}$ & $\begin{array}{c}1.815075 \\
(0.055274)\end{array}$ \\
\hline & 100 & $\begin{array}{l}14.798436 \\
(2.036059)\end{array}$ & $\begin{array}{c}1.988878 \\
(0.693329)\end{array}$ & $\begin{array}{c}1.772787 \\
(0.501844) \\
\end{array}$ & $\begin{array}{c}14.816299 \\
(0.035725)\end{array}$ & $\begin{array}{c}2.013080 \\
(0.048404)\end{array}$ & $\begin{array}{c}1.791505 \\
(0.037436) \\
\end{array}$ \\
\hline \multirow{3}{*}{$\begin{array}{c}(1.5,20.0 \\
1.8)\end{array}$} & 50 & $\begin{array}{c}1.764439 \\
(0.678689)\end{array}$ & $\begin{array}{l}20.909733 \\
(3.000343)\end{array}$ & $\begin{array}{c}1.825100 \\
(0.466971)\end{array}$ & $\begin{array}{c}1.813201 \\
(0.097523)\end{array}$ & $\begin{array}{l}21.356375 \\
(0.893284)\end{array}$ & $\begin{array}{c}1.859620 \\
(0.069039)\end{array}$ \\
\hline & 70 & $\begin{array}{c}1.654596 \\
(0.570268) \\
\end{array}$ & $\begin{array}{l}20.494443 \\
(2.472915)\end{array}$ & $\begin{array}{c}1.782673 \\
(0.444995) \\
\end{array}$ & $\begin{array}{c}1.691527 \\
(0.073863) \\
\end{array}$ & $\begin{array}{r}20.820860 \\
(0.652835) \\
\end{array}$ & $\begin{array}{c}1.807923 \\
(0.050500) \\
\end{array}$ \\
\hline & 100 & $\begin{array}{c}1.470724 \\
(0.412145)\end{array}$ & $\begin{array}{l}20.276260 \\
(1.910778)\end{array}$ & $\begin{array}{c}1.726960 \\
(0.389391)\end{array}$ & $\begin{array}{c}1.491756 \\
(0.042064)\end{array}$ & $\begin{array}{l}20.502736 \\
(0.452954)\end{array}$ & $\begin{array}{c}1.744505 \\
(0.035089)\end{array}$ \\
\hline \multirow{3}{*}{$\begin{array}{c}(1.5,2.0 \\
18.0)\end{array}$} & 50 & $\begin{array}{c}1.772303 \\
(0.835407) \\
\end{array}$ & $\begin{array}{c}1.883068 \\
(0.144065) \\
\end{array}$ & $\begin{array}{c}18.628263 \\
(3.817678)\end{array}$ & $\begin{array}{c}1.821281 \\
(0.097957) \\
\end{array}$ & $\begin{array}{c}1.923291 \\
(0.080446)\end{array}$ & $\begin{array}{l}18.750063 \\
(0.243599) \\
\end{array}$ \\
\hline & 70 & $\begin{array}{c}1.661970 \\
(0.701950)\end{array}$ & $\begin{array}{c}1.942809 \\
(0.118740)\end{array}$ & $\begin{array}{c}18.013267 \\
(3.638018)\end{array}$ & $\begin{array}{c}1.699065 \\
(0.074190)\end{array}$ & $\begin{array}{c}1.973752 \\
(0.061887)\end{array}$ & $\begin{array}{l}18.113067 \\
(0.199600)\end{array}$ \\
\hline & 100 & $\begin{array}{c}1.575350 \\
(0.603767)\end{array}$ & $\begin{array}{c}2.006331 \\
(0.111317)\end{array}$ & $\begin{array}{l}17.919767 \\
(3.340638)\end{array}$ & $\begin{array}{c}1.597879 \\
(0.045058)\end{array}$ & $\begin{array}{c}2.028740 \\
(0.044820)\end{array}$ & $\begin{array}{l}17.983279 \\
(0.127023)\end{array}$ \\
\hline \multirow{3}{*}{$\begin{array}{c}(15.0,20.0, \\
18.0)\end{array}$} & 50 & $\begin{array}{r}15.406360 \\
(5.281106)\end{array}$ & $\begin{array}{l}20.739119 \\
(1.153905)\end{array}$ & $\begin{array}{c}16.752523 \\
(1.772997)\end{array}$ & $\begin{array}{c}15.832127 \\
(0.851534)\end{array}$ & $\begin{array}{l}20.866310 \\
(0.254381)\end{array}$ & $\begin{array}{r}16.969363 \\
(0.433680) \\
\end{array}$ \\
\hline & 70 & $\begin{array}{l}15.169615 \\
(4.437442)\end{array}$ & $\begin{array}{c}0.541188 \\
(0.951061)\end{array}$ & $\begin{array}{c}17.344868 \\
(1.689560)\end{array}$ & $\begin{array}{l}15.508205 \\
(0.677180)\end{array}$ & $\begin{array}{l}20.646636 \\
(0.210896)\end{array}$ & $\begin{array}{r}17.475846 \\
(0.261956)\end{array}$ \\
\hline & 100 & $\begin{array}{l}15.007513 \\
(3.207037)\end{array}$ & $\begin{array}{l}20.322507 \\
(0.734868)\end{array}$ & $\begin{array}{l}17.642944 \\
(1.478440)\end{array}$ & $\begin{array}{l}15.222133 \\
(0.429240)\end{array}$ & $\begin{array}{l}20.406521 \\
(0.168029)\end{array}$ & $\begin{array}{l}17.744411 \\
(0.202934)\end{array}$ \\
\hline
\end{tabular}


Table 5: 95\% credible intervals for parameters of the GG distribution under Jeffreys prior

\begin{tabular}{|c|c|c|c|c|}
\hline$(\alpha, \beta$ & $\mathrm{n}$ & $\hat{\alpha}$ & $\hat{\beta}$ & $\hat{\mu}$ \\
\hline \multirow{3}{*}{$\begin{array}{l}(1.5 \\
2.0 \\
1.8)\end{array}$} & 50 & $\begin{array}{c}(0.170723,3.289033) \\
\delta=3.118309\end{array}$ & $\begin{array}{c}(0.405232,3.239440) \\
\delta=2.834207\end{array}$ & $\begin{array}{c}(0.792692,2.957300) \\
\delta=2.164608\end{array}$ \\
\hline & 70 & $\begin{array}{c}(0.312108,2.932264) \\
\delta=2.620155\end{array}$ & $\begin{array}{c}(0.712157,3.048143) \\
\delta=2335987\end{array}$ & $\begin{array}{c}(0.800037,2.862781) \\
\delta=2062743\end{array}$ \\
\hline & 100 & $\begin{array}{r}(0.410804,2.6 \\
\delta=22536\end{array}$ & $\begin{array}{r}(0.886275,3.0 \\
\delta=21899\end{array}$ & $\begin{array}{c}(0.869335,2.763463) \\
\delta=1894128\end{array}$ \\
\hline \multirow{3}{*}{$\begin{array}{c}(15.0, \\
2.0 \\
1.8)\end{array}$} & 50 & $\begin{array}{c}(7.769977,20.602705) \\
\delta=12.832728\end{array}$ & $\begin{array}{c}(0.017313,3.611075) \\
\delta=3.593762\end{array}$ & $\begin{array}{c}(0.650803,3.053233) \\
\delta=2.402431\end{array}$ \\
\hline & 70 & $\begin{array}{c}(9.375194,20.157876) \\
\delta=10.782681\end{array}$ & $\begin{array}{c}(0.390741,3.352759) \\
\delta=2.962019\end{array}$ & $\begin{array}{c}(0.664278,2.953652) \\
\delta=2.289374\end{array}$ \\
\hline & 100 & $\begin{array}{c}(10.286505 \\
\delta=9.274497\end{array}$ & $\begin{array}{c}(0.583977,3.360815) \\
\delta=2.776838\end{array}$ & $\begin{array}{c}(0.743021,2.845255) \\
\delta=2.102233\end{array}$ \\
\hline \multirow{3}{*}{$\begin{array}{c}(1.5 \\
20.0 \\
1.8)\end{array}$} & 50 & $\begin{array}{c}(0.233625,3.325137) \\
\delta=3.091512\end{array}$ & $\begin{array}{c}(14.728146,26.744760) \\
\delta=12.016615\end{array}$ & $\begin{array}{c}(0.869006,2.825156) \\
\delta=1.956151\end{array}$ \\
\hline & 70 & $\begin{array}{r}(0.369788,2.9 \\
\delta=2.5976\end{array}$ & $\begin{array}{r}(15.372493,25 \\
\delta=9.904\end{array}$ & $\begin{array}{c}(0.872096,2.736190) \\
\delta=1.864093\end{array}$ \\
\hline & 100 & $\begin{array}{r}(0.544493,2.4 \\
\delta=1.8773\end{array}$ & $\begin{array}{r}(16.281819,23 \\
\delta=7.6528\end{array}$ & $\begin{array}{c}(0.932176,2.563342) \\
\delta=1.631167\end{array}$ \\
\hline \multirow{3}{*}{$\begin{array}{c}(1.5, \\
2.0 \\
18.0)\end{array}$} & 50 & $\begin{array}{c}(0.039941,3.690003) \\
\delta=3.650061\end{array}$ & $\begin{array}{c}(1.578967,2.155959) \\
\delta=0.576993\end{array}$ & $\begin{array}{c}(10.856452,26.848778) \\
\delta=15.992326\end{array}$ \\
\hline & 70 & $\begin{array}{c}(0.077309,3.274779) \\
\delta=3.197470\end{array}$ & $\begin{array}{c}(1.688928,2.164490) \\
\delta=0.475563\end{array}$ & $\begin{array}{c}(10.610349,25.850075) \\
\delta=15.239725\end{array}$ \\
\hline & & $\begin{array}{c}(0.213574,2.963806) \\
\delta=2.750233\end{array}$ & $\begin{array}{c}(1.766787,2.212621) \\
\delta=0.445833\end{array}$ & $\begin{array}{c}(11.138588,25.132584) \\
\delta=13.993996\end{array}$ \\
\hline \multirow{3}{*}{$\begin{array}{l}(15.0, \\
20.0, \\
18.0)\end{array}$} & 50 & $\begin{array}{c}(3.508783,27.564867) \\
\delta=24.056084\end{array}$ & $\begin{array}{c}(18.256511,22.877995) \\
\delta=4.621484\end{array}$ & $\begin{array}{c}(13.240725,20.667843) \\
\delta=7.427118\end{array}$ \\
\hline & 70 & $\begin{array}{c}(5.191529,25.404621) \\
\delta=20.213092\end{array}$ & $\begin{array}{c}(18.466424,22.275500) \\
\delta=3.809076\end{array}$ & $\begin{array}{c}(14.014963,21.092563) \\
\delta=7.077599\end{array}$ \\
\hline & 100 & $\begin{array}{c}(7.830378,22.438822) \\
\delta=14.608444\end{array}$ & $\begin{array}{c}(18.682490,21.625696) \\
\delta=2.943207\end{array}$ & $\begin{array}{c}(14.758823,20.952035) \\
\delta=6.193212\end{array}$ \\
\hline
\end{tabular}


Table 6: 95\% credible intervals for parameters of the GG distribution under gamma prior

\begin{tabular}{|c|c|c|c|c|}
\hline$(\alpha, \beta$, & $\mathrm{N}$ & $\hat{\alpha}$ & $\hat{\beta}$ & $\hat{\mu}$ \\
\hline $\mathrm{II}$ & & $(0.288977,3.106073)$ & $(0.497907,3.189035)$ & $(0.795933,2.940797)$ \\
& 50 & $\delta=2.817096$ & $\delta=2.691127$ & $\delta=2.144863$ \\
$(1.5$, & & $(0.408316,2.775378)$ & $(0.792926,3.010985)$ & $(0.802968,2.846896)$ \\
2.0, & 70 & $\delta=2.367062$ & $\delta=2.218059$ & $\delta=2.043927$ \\
$1.8)$ & & $(0.490893,2.526870)$ & $(0.964531,3.043919)$ & $(0.871550,2.748400)$ \\
& 100 & $\delta=2.035978$ & $\delta=2.079388$ & $\delta=1.876851$ \\
\hline & & $(8.124446,19.717597)$ & $(0.129066,3.541403)$ & $(0.655210,3.035726)$ \\
& 50 & $\delta=11.593151$ & $\delta=3.412337$ & $\delta=2.380516$ \\
\cline { 2 - 5 }$(15.0$, & & $(9.619800,19.360929)$ & $(0.487215,3.299701)$ & $(0.668322,2.936813)$ \\
2.0, & 70 & $\delta=9.741129$ & $\delta=2.812486$ & $\delta=2.268491$ \\
\cline { 2 - 5 } 1.8$)$ & & $(10.455328$, & $(0.676944,3.313598)$ & $(0.746264,2.829322)$ \\
& 100 & $\delta=8.378627$ & $\delta=2.636654$ & $\delta=2.083057$ \\
\hline & & $(0.349658,3.142546)$ & $(15.271961,26.681938)$ & $(0.871395,2.809702)$ \\
& 50 & $\delta=2.792888$ & $\delta=11.409977$ & $\delta=1.938307$ \\
\cline { 2 - 6 }$(1.5$, & & $(0.464040,2.810760)$ & $(15.858212,25.262436)$ & $(0.874218,2.721307)$ \\
20.0, & 70 & $\delta=2.346720$ & $\delta=9.404224$ & $\delta=1.847089$ \\
\cline { 2 - 5 } 1.8$)$ & & $(0.607426,2.303452)$ & $(16.708199,23.974680)$ & $(0.933434,2.549722)$ \\
& 100 & $\delta=1.696026$ & $\delta=7.266481$ & $\delta=1.616288$ \\
\hline & & $(0.175301,3.472785)$ & $(1.615189,2.163053)$ & $(10.862718,26.709166)$ \\
& 50 & $\delta=3.297484$ & $\delta=0.547864$ & $\delta=15.846448$ \\
\cline { 2 - 5 }$(1.5$, & & $(0.200393,3.089003)$ & $(1.723277,2.174832)$ & $(10.615384,25.716096)$ \\
2.0, & 70 & $\delta=2.888610$ & $\delta=0.451555$ & $\delta=15.100712$ \\
\cline { 2 - 5 } 18.0$)$ & & $(0.316690,2.801265)$ & $(1.801117,2.224443)$ & $(11.138276,25.004622)$ \\
& 100 & $\delta=2.484574$ & $\delta=0.423326$ & $\delta=13.866346$ \\
\hline & & $(4.380054,26.112442)$ & $(18.611699,22.999875)$ & $(13.214640,20.574009)$ \\
& 50 & $\delta=21.732388$ & $\delta=4.388176$ & $\delta=7.359370$ \\
\cline { 2 - 5 }$(15.0$, & & $(5.881658,24.142268)$ & $(18.798829,22.415610)$ & $(13.985164,20.998203)$ \\
20.0, & 70 & $\delta=18.260610$ & $\delta=3.616781$ & $\delta=7.013039$ \\
\cline { 2 - 5 } 18.0$)$ & 100 & $(8.252874,21.450217)$ & $(18.990523,21.785147)$ & $(14.723923,20.860642)$ \\
& & $\delta=13.197343$ & $\delta=2.794624$ & $\delta=6.136719$ \\
\hline & & & & \\
\hline
\end{tabular}


Table 7: 95\% credible intervals for parameters of the GG distribution under inverse levy prior

\begin{tabular}{|c|c|c|c|c|}
\hline$(\alpha, \beta$ & $\mathrm{n}$ & $\hat{\alpha}$ & $\hat{\beta}$ & $\hat{\mu}$ \\
\hline \multirow{3}{*}{$\begin{array}{l}(1.5 \\
2.0 \\
1.8)\end{array}$} & 50 & $\begin{array}{c}(0.373591,3.057113) \\
\delta=2.683522\end{array}$ & $\begin{array}{c}(0.450564,3.224564) \\
\delta=2.774000\end{array}$ & $\begin{array}{c}(0.839884,2.865482) \\
\delta=2.025597\end{array}$ \\
\hline & 70 & $\begin{array}{c}(0.481151,2.735977) \\
\delta=2.254826\end{array}$ & $\begin{array}{c}(0.752679,3.039043) \\
\delta=2.286363\end{array}$ & $\begin{array}{c}(0.844478,2.774752) \\
\delta=1.930274\end{array}$ \\
\hline & 100 & $\begin{array}{c}(0.555007,2.494448) \\
\delta=1.939441\end{array}$ & $\begin{array}{c}(0.926092,3.069514) \\
\delta=2.143422\end{array}$ & $\begin{array}{c}(0.908540,2.681027) \\
\delta=1.772487\end{array}$ \\
\hline \multirow{3}{*}{$\begin{array}{c}(15.0 \\
2.0 \\
1.8)\end{array}$} & 50 & $\begin{array}{c}(8.545488,19.588945) \\
\delta=11.043456\end{array}$ & $\begin{array}{c}(0.070644,3.588064) \\
\delta=3.517419\end{array}$ & $\begin{array}{c}(0.705905,2.954052) \\
\delta=2.248147\end{array}$ \\
\hline & 70 & $\begin{array}{c}(10.002914,19.282163) \\
\delta=9.279249\end{array}$ & $\begin{array}{c}(0.437843,3.336939) \\
\delta=2.899096\end{array}$ & $\begin{array}{c}(0.716262,2.858613) \\
\delta=2.142351\end{array}$ \\
\hline & 100 & $\begin{array}{c}(10.807761,18.789112) \\
\delta=7.981351\end{array}$ & $\begin{array}{c}(0.629953,3.347803) \\
\delta=2.717849\end{array}$ & $\begin{array}{c}(0.789173,2.756401) \\
\delta=1.967228\end{array}$ \\
\hline \multirow{3}{*}{$\begin{array}{c}(1.5 \\
20.0 \\
1.8)\end{array}$} & 50 & $\begin{array}{c}(0.434209,3.094670) \\
\delta=2.660461\end{array}$ & $\begin{array}{c}(15.029061,26.790406) \\
\delta=11.761345\end{array}$ & $\begin{array}{c}(0.909837,2.740364) \\
\delta=1.830527\end{array}$ \\
\hline & 70 & $\begin{array}{c}(0.536871,2.772320) \\
\delta=2.235449\end{array}$ & $\begin{array}{c}(15.647530,25.341355) \\
\delta=9.693825\end{array}$ & $\begin{array}{c}(0.910483,2.654864) \\
\delta=1.744381\end{array}$ \\
\hline & 100 & $\begin{array}{c}(0.662920,2.278528) \\
\delta=1.615608\end{array}$ & $\begin{array}{c}(16.531134,24.021385) \\
\delta=7.490251\end{array}$ & $\begin{array}{c}(0.963753,2.490167) \\
\delta=1.526413\end{array}$ \\
\hline \multirow{3}{*}{$\begin{array}{c}(1.5, \\
2.0, \\
18.0)\end{array}$} & 50 & $\begin{array}{c}(0.268569,3.409701) \\
\delta=3.141132\end{array}$ & $\begin{array}{c}(1.600700,2.165436) \\
\delta=0.564736\end{array}$ & $\begin{array}{c}(11.145614,26.110913) \\
\delta=14.965300\end{array}$ \\
\hline & 70 & $\begin{array}{c}(0.286147,3.037793) \\
\delta=2.751645\end{array}$ & $\begin{array}{c}(1.710079,2.175539) \\
\delta=0.465460\end{array}$ & $\begin{array}{c}(10.882752,25.143783) \\
\delta=14.261031\end{array}$ \\
\hline & 100 & $\begin{array}{c}(0.391966,2.758733) \\
\delta=2.366767\end{array}$ & $\begin{array}{c}(1.788149,2.224512) \\
\delta=0.436362\end{array}$ & $\begin{array}{c}(11.372116,24.467418) \\
\delta=13.095302\end{array}$ \\
\hline \multirow{3}{*}{$\begin{array}{l}(15.0, \\
20.0, \\
18.0)\end{array}$} & 50 & $\begin{array}{c}(5.055392,25.757329) \\
\delta=20.701936\end{array}$ & $\begin{array}{c}(18.477465,23.000774) \\
\delta=4.523309\end{array}$ & $\begin{array}{c}(13.277449,20.227598) \\
\delta=6.950149\end{array}$ \\
\hline & 70 & $\begin{array}{c}(6.472228,23.867002) \\
\delta=17.394774\end{array}$ & $\begin{array}{c}(18.677108,22.405268) \\
\delta=3.728159\end{array}$ & $\begin{array}{c}(14.033330,20.656406) \\
\delta=6.623076\end{array}$ \\
\hline & 100 & $\begin{array}{c}(8.721721,21.293305) \\
\delta=12.571585\end{array}$ & $\begin{array}{c}(18.882165,21.762849) \\
\delta=2.880684\end{array}$ & $\begin{array}{c}(14.745202,20.540686) \\
\delta=5.795484\end{array}$ \\
\hline
\end{tabular}

Tables 1-7 contain the Bayes estimates, posterior risks and $95 \%$ credible intervals for the parameters of the GG distribution under Jeffreys, gamma and inverse levy priors using squares error and precautionary loss functions. The parameters have been over/under estimated in different cases. However by increasing the sample size, the estimated values of the parameters converge to the true values of the parameters, and amounts of posterior risks associated with these estimates tend to decrease. This simply indicates that the proposed estimators are consistent in nature. On the whole, the performance of the precautionary loss function and inverse levy prior is better than their competitors. The increase (decrease) in the value of parameter ' $\alpha$ ' imposes a negative (positive) impact on the estimation of the parameters ' $\beta$ ' and ' $\mu$ '. The increase (decrease) in the value of parameter ' $\beta$ ' imposes a positive (negative) impact on the estimation of the parameters 
' $\alpha$ ' and ' $\mu$ '. The increase (decrease) in the value of parameter ' $\mu$ ' imposes a negative (positive) impact on the estimation of the parameter ' $\alpha$ ', while it imposes a positive (negative) impact on the estimation of the parameter ' $\mu$ '. The interval estimation (credible intervals) of the parameters has been presented in the tables 5-7. The credible intervals tend to be more specific in larger samples. The interval estimation is more accurate under inverse levy prior.

\section{Real Life Example}

In this section a real life data set has been used for the analysis in order to discuss the practical applicability of the results obtained in the previous sections. A lifetime data set regarding the breaking strengths of 64 single carbon fibers of length 10, presented by Lawless (2003) has been used for this purpose. The data has been given in the table 7. We have used the Kolmogorov-Smirnov and chi square tests to see whether the data follow the GG distribution. These tests say that the data follow the GG distribution at 5\% level of significance with p-values0.1064 and 0.0914 respectively. We have also presented the P-P and Q-Q plots for the same data in figures 13-14, these figures also suggest the good fit of the GG distribution on the given data. The results of the analysis have been reported in the tables 8-9given below. The amounts of posterior risks associated with each estimate have been presented in the parenthesis below the estimates in the tables.

Table 7: The real life data set regarding the breaking strengths of 64 single carbon fibers of length 10

\begin{tabular}{|l|l|l|l|l|l|l|l|l|l|l|}
\hline 1.901 & 2.361 & 2.474 & 2.614 & 2.738 & 2.937 & 3.145 & 3.272 & 3.435 & 3.628 & 4.027 \\
2.132 & 2.396 & 2.518 & 2.616 & 2.740 & 2.977 & 3.220 & 3.294 & 3.493 & 3.852 & 4.225 \\
2.203 & 2.397 & 2.522 & 2.618 & 2.856 & 2.996 & 3.223 & 3.332 & 3.501 & 3.871 & 4.395 \\
2.228 & 2.445 & 2.525 & 2.624 & 2.917 & 3.030 & 3.235 & 3.346 & 3.537 & 3.886 & 5.020 \\
2.257 & 2.454 & 2.532 & 2.659 & 2.928 & 3.125 & 3.243 & 3.377 & 3.554 & 3.975 & \\
2.350 & 2.454 & 2.575 & 2.675 & 2.937 & 3.139 & 3.264 & 3.408 & 3.562 & 4.024 & \\
\hline
\end{tabular}

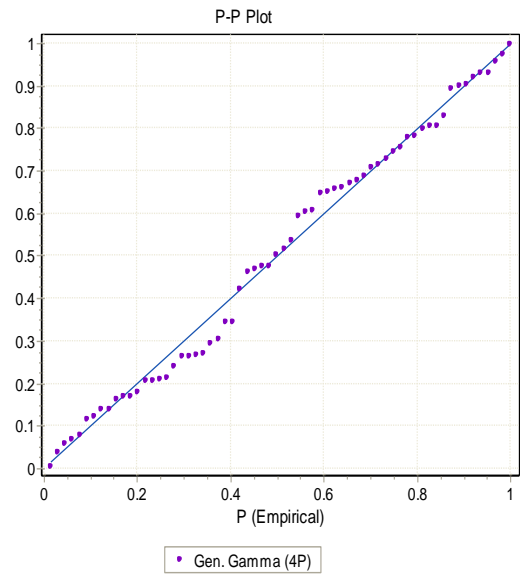

Fig. 13: P-P plot for the GG distribution using real life data

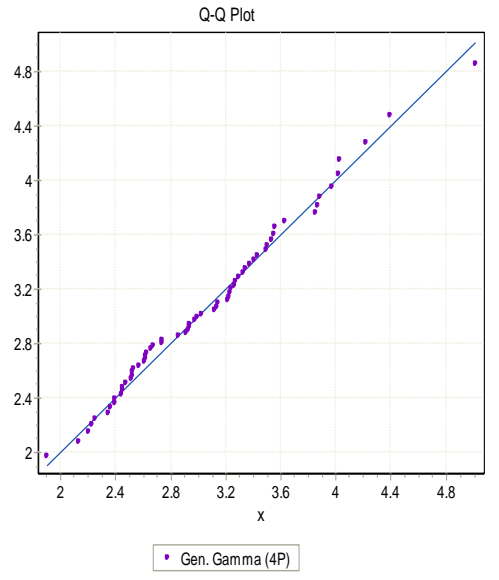

Fig. 14: Q-Q plot for the GG distribution using real life data 
Table 8: Bayes estimators and posterior risks under inverse levy prior using different loss functions

\begin{tabular}{|c|c|c|c|c|c|c|}
\hline \multirow{2}{*}{ Priors } & \multicolumn{3}{|c|}{ SELF } & \multicolumn{3}{c|}{ PLF } \\
\cline { 2 - 7 } & $\hat{\alpha}$ & $\hat{\beta}$ & $\hat{\mu}$ & $\hat{\alpha}$ & $\hat{\beta}$ & $\hat{\mu}$ \\
\hline \multirow{2}{*}{ Jeffreys } & 3.992734 & 0.578763 & 2.627926 & 4.111299 & 0.591481 & 2.682996 \\
& $(1.711639)$ & $(0.189163)$ & $(0.620193)$ & $(0.237130)$ & $(0.025435)$ & $(0.110139)$ \\
\hline \multirow{2}{*}{ Gamma } & 3.918060 & 0.585475 & 2.618632 & 4.013539 & 0.595157 & 2.661045 \\
& $(1.546303)$ & $(0.179613)$ & $(0.614536)$ & $(0.190958)$ & $(0.019364)$ & $(0.084826)$ \\
\hline Inverse & 3.959207 & 0.583599 & 2.596653 & 4.023874 & 0.590472 & 2.628289 \\
Levy & $(1.472985)$ & $(0.185145)$ & $(0.580364)$ & $(0.129336)$ & $(0.013746)$ & $(0.063271)$ \\
\hline
\end{tabular}

Table 9: 95\% credible intervals for parameters of the GG distribution under inverse levy prior

\begin{tabular}{|c|c|c|c|}
\hline Priors & $\hat{\alpha}$ & $\hat{\beta}$ & $\hat{\mu}$ \\
\hline \multirow{2}{*}{ Jeffreys } & $(0.637922,7.347546)$ & $(0.208004,0.949522)$ & $(1.412348$, \\
& $\delta=6.709625$ & $\delta=0.741519$ & $\delta .843504)$ \\
& & & $\delta=2.431157$ \\
\hline \multirow{2}{*}{ Gamma } & $(0.887305,6.948815)$ & $(0.233433,0.937518)$ & $(1.414142$, \\
& $\delta=6.061509$ & $\delta=0.704085$ & $\delta .823122)$ \\
\hline \multirow{2}{*}{ Inverse } & $(1.072157,6.846256)$ & $(0.220716,0.946483)$ & $(1.459139$, \\
Levy & $\delta=5.774100$ & $\delta=0.725767$ & $\delta .734167)$ \\
& \multicolumn{2}{|c|}{} \\
\hline
\end{tabular}

The analysis of the real life data replicated the patterns observed under simulation study. The Bayes estimates under precautionary loss function using inverse levy prior are the most efficient. The $95 \%$ credible intervals are also more accurate under inverse levy prior.

\section{Conclusion}

The study has been planned to discuss the Bayes estimation of the parameters of the GG distribution under different priors using a couple of loss functions. The estimation has been done using MCMC algorithm using WinBugs. After a detailed analysis it has been assessed that the Bayes estimators under the assumption of inverse levy prior based on precautionary loss function are the most efficient, as the amounts of the posterior risks associated with these estimates are the minimum and the widths of the corresponding 95\% credible intervals are the least. The analysis of the real life data further strengthened these findings. In future this work can be extended by considering censored samples instead of complete samples, and by comparing the results obtained under Gibbs sampler with those under Lindley's approximation.

\section{References}


1. Abadi, A., Amanpour, F., Bajdik, C. and Yavari, P. (2012). Breast cancer survival analysis: applying the generalized gamma distribution under different conditions of the proportional hazards and accelerated failure time assumptions. International Journal of Preventive Medicine, 3(9), 644-651.

2. Ali, M. M., Pal, M. and Woo, J. (2012). Estimation of $\mathrm{P}(\mathrm{Y}<\mathrm{X})$ in a FourParameter Generalized Gamma Distribution. Austrian Journal of Statistics, 41(3), 197-210.

3. Balakrishnan, N. and Chand, P. S. (1994). Asymptotic Best Linear Unbiased Estimation For The Log-Gamma Distribution, Sankhya : The Indian Journal of Statistics, 56, 314-322.

4. Chen, D. G. and Lio, Y. (2009). A Note on the Maximum Likelihood Estimation for the Generalized Gamma Distribution Parameters under Progressive Type-II Censoring, International Journal of Intelligent Technology and Applied Statistics, 2(2), 57-64.

5. Chung, Y. and Kang, Y. (1998). Bayesian Analysis in Generalized Log-Gamma Censored Regression Model, The Korean Communications in Statistics, 5(3), 733-742.

6. Devroye, L. (1984), A simple algorithm for generating random variates with a log-concave density, Computing, 33, 247-257.

7. Ergashev, B. (2009).Estimating the Lognormal-Gamma Model of Operational Risk Using the Markov Chain Monte Carlo Method, The Journal of Operational Risk, 4(1), 35-57.

8. Ghanizadeh, A., Pazira, H. and Lotfi, R. (2011). Classical estimations of the exponentiated gamma distribution parameters with presence of $\mathrm{k}$ outliers, Australian Journal of Basic and Applied Sciences, 5(3), 571-579.

9. Gomes, O.,Combes, C. and Dussauchoy, A. (2008). Parameter estimation of the generalized gamma distribution, Mathematics and Computers in Simulation, 79(4), 955-963.

10. Gupta, R. C., Gupta, R. D. and Gupta, P. L. (1998). Modeling failure time data by lehman alternatives, Commun. Statist.- Theory, Meth., 27(4), 887-904.

11. Khan, R. U. and Kumar, D. (2011). Lower generalized order statistics from exponentiated gamma distribution and its characterization, Prob Stat Forum, 4, 25-38.

12. Khodabin, M. and Ahmadabadi, A. (2010). Some properties of generalized gamma distribution, Mathematical Sciences, 4(1), 9-28.

13. Kumar, V. and Shukla, G. (2010). Maximum Likelihood Estimation in Generalized Gamma Type Model. Journal of Reliability and Statistical Studies,3(1), 43-51.

14. Mukherjee, B., Gupta, A. and Upadhyay, S. K. (2010). A Bayesian study for the comparison of generalized gamma model with its components, Sankhya B, 72, 154-174. 
15. Noufaily, A. and Jones, M. C. (2013). On maximization of the likelihood for the generalized gamma distribution, Computational Statistics,28(2), 505-517.

16. Persson, K. and Ryden, J. (2010). Exponentiated Gumbel distribution for estimation of return levels of significant wave height, Journal of Environmental Statistics, 1(3), 211-220.

17. Saha, A. and Shimamura, T. (2012). Perceptually Motivated Bayesian Estimators With Generalized Gamma Distribution Under Speech Presence Probability, International Journal Of Circuits, Systems And Signal Processing, 1(6), 105-112.

18. Samaniego, F.J. (2010). A comparison of Bayesian and Frequentist Approaches to Estimation, Speringer Series in Statistics.

19. Shawky, A. I. and Bakoban, R. A. (2008). Bayesian and non-Bayesian estimations on the exponentiated gamma distribution, Applied Mathematical Sciences, 2(51), 2521-2530.

20. Shawky, A. I. and Bakoban, R. A. (2009). Order statistics from exponentiated gamma distribution and associated inference, Int. J. Contemp. Math. Sciences, 4(2), 71-91.

21. Shawky, A. I. and Bakoban, R. A. (2009). On finite mixture of two-component exponentiated gamma distribution, Journal of Applied Sciences Research, 5(10), 1351-1369.

22. Singh, S. K., Singh, U. and Kumar, D. (2011). Bayesian estimation of the exponentiated gamma parameter and reliability function under asymmetric loss function, REVSTAT - Statistical Journal, 9(3), 247-260.

23. Xie, X. and Liu, X. (2009). Analytical three-moment autoconversion parameterization based on generalized gamma distribution, Journal Of Geophysical Research, 114, 1-8.

24. Zaks, L. M. and Korolev, V. Y. (2013). Variance-generalized-gammadistributions as limit laws for random sums, Inform. Primen., 7(1), 105-115. 